\title{
Influence of surface passivation on optical properties of spray pyrolysis deposited $\mathrm{Pd}-\mathrm{F}: \mathrm{SnO}_{2}$
}

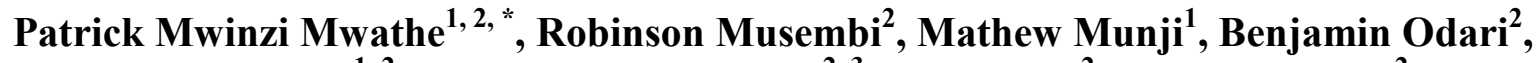 \\ Lawrence Munguti $^{1,2}$, Alex Alfred Ntilakigwa ${ }^{2,3}$, John Nguu ${ }^{2}$, Bernard Aduda ${ }^{2}$, \\ Boniface Muthoka ${ }^{2}$ \\ ${ }^{1}$ Department of Physics, Kenyatta University, P.O. Box 43844-00100, Nairobi, Kenya \\ ${ }^{2}$ Department of Physics, University of Nairobi, P.O Box 30197-00100, Nairobi, Kenya \\ ${ }^{3}$ Faculty of Science Technology and Environmental Studies, Open University of Tanzania, P.O. Box 31608, Dar es Salaam, Tanzania
}

\section{Email address:}

mwathepatrick@gmail.com (P. Mwathe), musembirj@uonbi.ac.ke (R. Musembi)

\section{To cite this article:}

Patrick Mwinzi Mwathe, Robinson Musembi, Mathew Munji, Benjamin Odari, Lawrence Munguti, Alex Alfred Ntilakigwa, John Nguu, Bernard Aduda, Boniface Muthoka. Influence of Surface Passivation on Optical Properties of Spray Pyrolysis Deposited Pd-F:SnO 2 . International Journal of Materials Science and Applications. Vol. 3, No. 5, 2014, pp. 137-142. doi: 10.11648/j.ijmsa.20140305.11

\begin{abstract}
Pd}-\mathrm{F}: \mathrm{SnO}_{2}$ thin films have been prepared by spray pyrolysis technique using an alcoholic precursor solution consisting of stannic chloride $\left(\mathrm{SnCl}_{4} .5 \mathrm{H}_{2} \mathrm{O}\right)$, ammonium fluoride $\left(\mathrm{NH}_{4} \mathrm{~F}\right)$ and palladium chloride $\left(\mathrm{PdCl}_{2}\right)$. Optimization on the deposition parameters has been done in order to obtain high quality thin films. The effect of varying the fluorine content on the optical properties of Pd-F: $\mathrm{SnO}_{2}$ thin films were studied. Data for transmittance and reflectance in the wavelength range from $300 \mathrm{~nm}-2500 \mathrm{~nm}$ was measured using the solid spec 3700DUV spectrophotometer. The calculated optical band gap of the as prepared thin films has been found to range from $3.8 \mathrm{eV}$ to $4.11 \mathrm{eV}$. Fluorine incorporation for $\mathrm{Pd}-\mathrm{F}: \mathrm{SnO}_{2}$ has been found to have a narrowing effect on the band gap, but at its higher concentration the band gap has been seen to increase. The band gap narrowing is due to the incorporation of $\mathrm{F}^{-}$ions in the crystal lattice therefore giving rise to donor levels in the $\mathrm{SnO}_{2}$ band gap which is an essential characteristic for the gas sensor applications. Both annealing and passivation have been found to have very insignificant change in optical band gap of Pd-F: $\mathrm{SnO}_{2}$.
\end{abstract}

Keywords: Spray Pyrolysis, Fluorine Doping, Palladium Doping, Co-Doping, Palladium and Fluorine Co-Doping, Annealing, Passivation, $\mathrm{Pd}$ and $\mathrm{F}$ Co-Doped $\mathrm{SnO}_{2}\left(\mathrm{Pd}-\mathrm{F}: \mathrm{SnO}_{2}\right)$

\section{Introduction}

Metal oxide semiconductor based devices have been a subject of a large number of scientific investigations in the recent past, especially those fabricated using $\mathrm{ZnO}, \mathrm{SnO}_{2}$ and $\mathrm{TiO}_{2}$ based thin films [1]. The $\mathrm{SnO}_{2}$ thin films have been reported in the literature to have excellent qualities which include high optical transparency, mechanical and chemical stabilities and high temperature resistant $[2,3]$. $\mathrm{SnO}_{2}$ based thin films have n-type conductivity that can be manipulated from normal to degenerate by suitably doping $\mathrm{SnO}_{2}$ thin films with appropriate amount of noble metal $(\mathrm{Pt}$, $\mathrm{Pd})$, semi-metal ( $\mathrm{Sb}, \mathrm{In}, \mathrm{Bi})$ and halogens (F, Cl) [4]. $\mathrm{SnO}_{2}$ based thin films are polycrystalline with tetragonal rutile structure and non-stoichiometric semiconductors [5, 6, 7]. Tin oxide can exist in two structures belonging to direct and indirect optical transitions, with different band gaps; a direct band gap that ranges from 3.6 to $4.6 \mathrm{eV}$ [8] at room temperature and indirect band gap of about 2.6eV [9]. Due to the high optical transmittance of $\mathrm{SnO}_{2}$ based thin films they are used in many areas which are not limited to the research laboratory but are used commercially in environmental monitoring, industrial electronic sensor and liquid crystal displays [2]. They have been used as a window layer for solar cells, opacities, thin film resistors, electric conversion thin films, surface protection on layers of glass, semiconductor hetero-junction structures, heat reflective semiconductor insulator, an overcoat for thin film magnetic media overcoat and as a material for Li-ion batteries $[6,7,10]$. $\mathrm{SnO}_{2}$ thin films do not easily react with 
oxygen and water vapour and can only be dissolved by hot alkalis [11], but suffer from instability arising from three main areas of concern that is surface contamination of the active part of the sensor, changes in sensor characteristics e.g. inter-granular connectivity which occurs due to thermal expansion coefficient mismatch and/or interfacial reactions at the metal electrode/ceramic interface. Lastly, the film morphology may change over time due to the relatively high operating temperatures of the sensor, which may also cause migration of additives [12].

A number of methods have been reported to improve on the stability of doped $\mathrm{SnO}_{2}$ thin films for gas sensor applications. Some of them include, thiourea treatment and use of metal catalysts e.g. $\mathrm{Pd}, \mathrm{Ru}, \mathrm{Pt}, \mathrm{Cu}, \mathrm{Ag}$ and $\mathrm{Au}[12$, 13]. Annealing of the thin films in air have been reported to improve the stability of $\mathrm{SnO}_{2}$ based thin films in time during the sensing of CO gas [14], however, annealing of thin films in air has the limitation of promoting oxidation and reduction of the oxygen vacancies which lead to loss in sensitivity of the thin films in detection of $\mathrm{CO}_{2}$ gas. In order to improve on the stability of the thin films for $\mathrm{CO}_{2}$ gas sensing applications while preventing the oxidation of the thin films and retaining the optimum sensitivity of the films, passivation of the doped $\mathrm{SnO}_{2}$ thin films in a nitrogen atmosphere is proposed.

Many methods have been used to deposit $\mathrm{SnO}_{2}$ based thin films which include RF magnetron sputtering [15], chemical vapour deposition method [16], Electron Beam evaporation method [17], Flash evaporation technique [18], Dip coating technique [10] and the Spray pyrolysis technique [19]. In this study spray pyrolysis deposition technique has been chosen because this technique is economical, promotes large area deposition allowing easy doping of the thin films hence the process is scalable and can be utilized for large scale production of high quality thin films [19]. The $\mathrm{SnO}_{2}$ were doped with fluorine in order to improve on the charge carrier concentration and with palladium to improve on their stability and sensitivity toward $\mathrm{CO}_{2}$ gas. Since passivation is known to improve on the stability of $\mathrm{SnO}_{2}$ based thin films $[14,20,21,22]$, the main purpose of this study was to deposit $\mathrm{Pd}-\mathrm{F}: \mathrm{SnO}_{2}$ thin films for $\mathrm{CO}_{2}$ gas sensing and study the effect of surface passivation on the optical properties of $\mathrm{Pd}-\mathrm{F}: \mathrm{SnO}_{2}$ thin films.

\section{Experimental Procedure}

\subsection{Sample Preparation}

The substrate used were ordinary microscope glass slides measuring $2.5 \mathrm{~cm}$ by $7.6 \mathrm{~cm}$ and $1.2 \mathrm{~mm}$ thick. Cleaning of the substrates was done prior to deposition. The substrates were first soaked in soapy water solution and sonicated for 30 minutes. They were removed and rinsed using distilled water. After rinsing, the substrates were immersed in distilled water in a beaker and sonicated for another 30 minutes. They were removed and rinsed in distilled water and left to dry. After drying the substrates were stored in a desiccator ready to be used for coating.

\subsection{Thin Film Deposition}

Spray pyrolysis technique was used to coat the films. The experimental set up used is a Lab assembled spray pyrolysis system as shown in Fig 1 below. It consisted of a hot plate, spray nozzle of diameter $\sim 1 \mathrm{~mm}$, input gas valve, gas compressor, gas flow meter, conduit tube, thermocouple and a pressure gauge, and deposition was performed inside the fume chamber. The following Table 1 contains the optimized deposition parameters.

Table 1. Optimized deposition parameters

\begin{tabular}{ccc}
\hline S/N & Deposition parameters & Optimized condition \\
\hline 1 & Pressure of carrier gas & $1.5 \mathrm{bar}$ \\
2 & Substrate temperature & $450 \pm 10^{\circ} \mathrm{C}$ \\
3 & Flow rate & $4 \mathrm{ml} / \mathrm{min}$ \\
4 & Quantity of spraying solution & $30 \mathrm{~cm}^{3}$ \\
5 & Nozzle to substrate distant & $33 \pm 3 \mathrm{~cm}$ \\
\hline
\end{tabular}

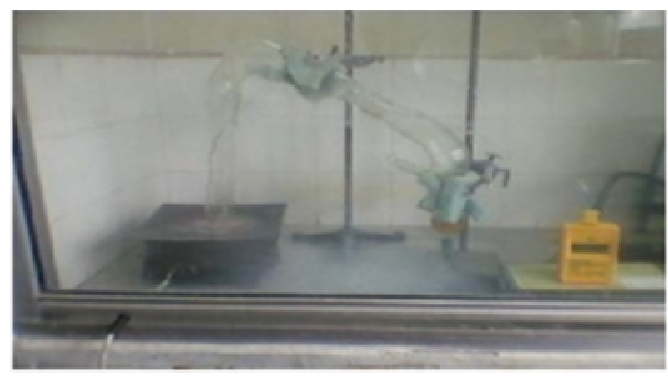

Figure 1. Spray pyrolysis experimental set up.

The undoped $\mathrm{SnO}_{2}$ thin films were deposited using a precursor solution consisting of Tin (IV) chloride (98\%) prepared by completely dissolving $5 \mathrm{~g}$ of stannic chloride in $100 \mathrm{ml}$ of ethanol (99.9\%). $0.5 \mathrm{~g}$ of $\mathrm{PdCl}_{2}(59-60 \% \mathrm{Pd})$ was completely dissolved in $60 \mathrm{ml}$ of ethanol (99.9\%). It was then added to stannic chloride solution at different doping concentrations ranging $(1.8 \mathrm{at} \%-6.9 \mathrm{at} \% \mathrm{Pd})$ in order to get Pd: $\mathrm{SnO}_{2}$ thin films. $1.0 \mathrm{~g}$ of ammonium fluoride $\left(\mathrm{NH}_{4} \mathrm{~F}\right)$ was added to distilled water in order to make $\mathrm{NH}_{4} \mathrm{~F}$ solution. $\mathrm{NH}_{4}$ Fsolution was then added to the spraying/starting solution containing stannic chloride from $0 \mathrm{at} \%$ to $22.74 \mathrm{at} \%$ Fand $2.7 \mathrm{at} \% \mathrm{Pd}$ at varying doping concentrations ranging from $0-19.28 \mathrm{at} \% \mathrm{~F}$ in order to make $\mathrm{Pd}-\mathrm{F}: \mathrm{SnO}_{2}$ thin films.

\subsection{Annealing of Thin Films}

Thin films were annealed in a tube furnace (schematic diagram shown in Fig 2), in the presence of air at $450^{\circ} \mathrm{C}$ for 30 minutes. This was done in order to improve the microstructure and crystallinity of the coatings. Apart from hardening and sintering the coatings, annealing was done in order to improve on the electrical conductivity of Pd-F: $\mathrm{SnO}_{2}$ the thin films. 


\subsection{Thin Film Passivation}

Thin films were passivated by annealing them in a nitrogen atmosphere in a tube furnace for 30 minutes at $450^{\circ} \mathrm{C}$. Since passivation is known to improve on the stability of doped $\mathrm{SnO}_{2}$ thin films [13, 14, 20, 21, 22], in this study it was done in order to study its effect on optical properties of $\mathrm{Pd}-\mathrm{F}: \mathrm{SnO}_{2}$ thin films.

\subsection{Optical Characterization}

Optical characterization of the thin films was done using Shimadzu model type DUV3700 spectrophotometer for un-polarized light. Data for both transmittance and reflectance at wavelength range $300 \mathrm{~nm}-2500 \mathrm{~nm}$ was collected. Analysis of the collected data was done using pre-developed models in Scout 98 software. The models used were the Harmonic Oscillator model, Drude Model and the OJL model. The models were used to fit simulated theoretical data into experimental data and hence optical properties were calculated, that is band gap, refractive index and extinction coefficient. The graphs were drawn using the Origin Pro 8.1 software.

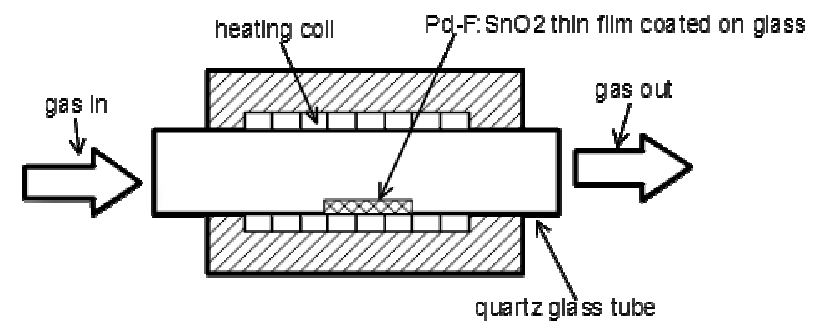

Figure 2. Horizontal tube furnace for annealing and passivation.

\section{Results and Discussion}

\subsection{Optical Properties}

The transmittance and reflectance measurements which were done as a function of wavelength was used to determine the effect of passivation on bare and doped $\mathrm{SnO}_{2}$ thin films.

\section{2. $\mathrm{SnO}_{2}$ and Pd:SnO $\mathrm{O}_{2}$ Thin Films}

Fig 3 shows the transmittance and reflectance spectra of both undoped and palladium doped tin oxide. The average transmittance of the thin films was $84.7 \%$ within the visible part of the spectrum. The optical transmittance was observed to decrease from $81.73 \%$ at $749 \mathrm{~nm}$ for undoped $\mathrm{SnO}_{2}$ to $80.61 \%$ at $763 \mathrm{~nm}$. This was as a result of 2.7 at $\% \mathrm{Pd}$ doping in $\mathrm{SnO}_{2}$ thin films. The decrease in transmittance is due to increase in photon absorption as photon striking increases with increase in carrier concentration [23]. A maximum transmittance of $87.79 \%$ at $735 \mathrm{~nm}$ was recorded for $1.8 \mathrm{at} \%$ $\mathrm{Pd}$ doping in $\mathrm{SnO}_{2}$ thin films. This high transmittance is attributed to decrease in diffuse and multiple reflections caused by increase in grain size and a reduction in light-scattering effect [4]. A sharp fall in transmittance at
$310 \mathrm{~nm}$ is due to absorption of the glass substrate [24]. The reflectance of the thin films was below $22 \%$ within the visible spectrum.

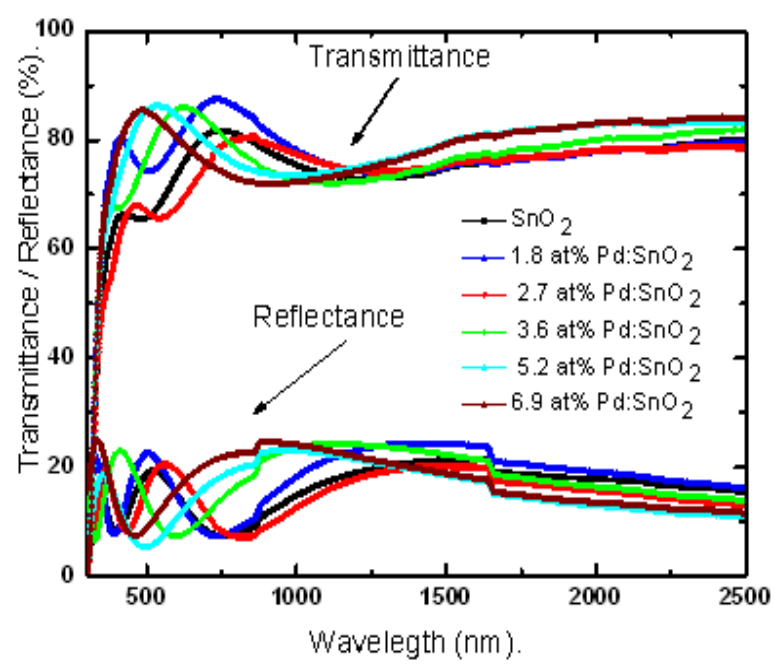

Figure 3. Transmittance and reflectance spectra for bare and $\mathrm{Pd}: \mathrm{SnO}_{2}$

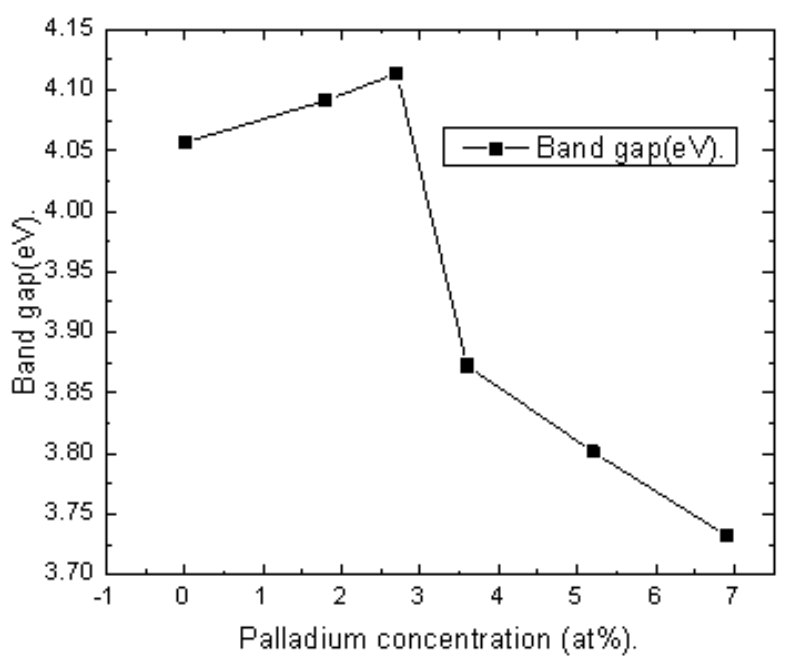

Figure 4. Optical Band gap for $\mathrm{Pd}: \mathrm{SnO}_{2}$ thin films

Fig. 4 shows a graph of optical band gaps for palladium doped tin oxide at different doping levels. The band gap of undoped $\mathrm{SnO}_{2}$ thin film was found to be $4.0564 \mathrm{eV}$, and on doping with 1.8 at $\% \mathrm{Pd}$, the band gap was observed to increase slightly to $4.0913 \mathrm{eV}$. The maximum band gap widening was $4.1135 \mathrm{eV}$ after doping $\mathrm{SnO}_{2}$ with $2.7 \mathrm{at} \% \mathrm{Pd}$, the band gap widening effect can be attributed to the Burstein-Moss effect which states that: Increase in free carrier concentration, due to the high doping levels, fills empty states belonging to conduction band of the thin films thereby increasing the energy magnitude required for the valence band to conduction band transitions as reported by Sánchez-García et al., 2012 [25]. Higher doping level with palladium from $3.6 \mathrm{at} \% \mathrm{Pd}-6.9 \mathrm{at} \% \mathrm{Pd}$, the band gap is observed to start decreasing which is in good agreement with results obtained by Odari et al., 2013 [26] and Fatema et al., (2011) [27] for the similar materials. 


\section{3. $\mathrm{SnO}_{2}$ and $\mathrm{F}: \mathrm{SnO}_{2}$ Films}

Fig. 5 shows the transmittance and reflectance spectra as a function of wavelength for $\mathrm{F}: \mathrm{SnO}_{2}$ thin films. The $\mathrm{SnO}_{2}$ thin films were doped with fluorine. Different thin films were prepared and analyzed. The different thin films had different level of dopant concentration ranging from $0 \mathrm{at} \% \mathrm{~F}$ doping to $22.74 \mathrm{at} \% \mathrm{~F}$ doping.

It is clearly seen that, from $1000 \mathrm{~nm}$ to $2500 \mathrm{~nm}$, when $\mathrm{SnO}_{2}$ is doped with fluorine, its antireflective properties are improved. There is a slight decrease in reflectance while at the same time transmittance improves in that region. Average transmittance of the thin films was $84.28 \%$ in the visible range of the spectrum. A maximum transmittance of $89.5 \%$ was obtained at $12.83 \mathrm{at} \% \mathrm{~F}$ doping in $\mathrm{SnO}_{2}$ thin films. The same reasons attributed to increment and decrement of transmittance at different level of doping applies in this case as it was deduced for palladium doping. Reflectance spectra of the $\mathrm{F}: \mathrm{SnO}_{2}$ thin films was found to be below $22 \%$ in the measured wavelength range.

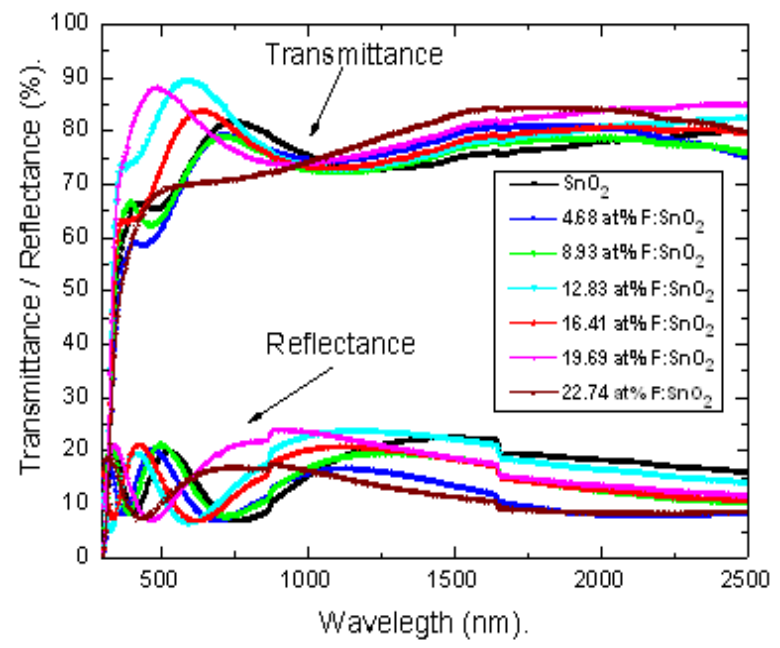

Figure 5. Transmittance and reflectance spectra for undoped and $\mathrm{F}: \mathrm{SnO}_{2}$

In fig. 6, the variation of the calculated band gap for various thin films at certain doping levels is shown. The undoped $\mathrm{SnO}_{2}$ thin film band gap was calculated to be about $4.0564 \mathrm{eV}$. When the $\mathrm{SnO}_{2}$ was doped with fluorine at 4.68at $\% \mathrm{~F}$ concentration, the band gap was observed to decrease to $4.0296 \mathrm{eV}$. This decrease in band gap continued upto a minima of about $3.8014 \mathrm{eV}$ where the doping level was $16.41 \mathrm{at} \% \mathrm{~F}$ concentration. Increase in the fluorine dopant concentration from zero to the optimum level $(16.41 \mathrm{at} \% \mathrm{~F})$ caused a narrowing effect on the band gap. The narrowing effect on the band gap can be attributed to the incorporation of $\mathrm{F}^{-}$ions in the crystal lattice, which gives rise to donor levels in the $\mathrm{SnO}_{2}$ band gap. This causes the conduction band to lengthen which leads to a reduction in the band gap value [15].

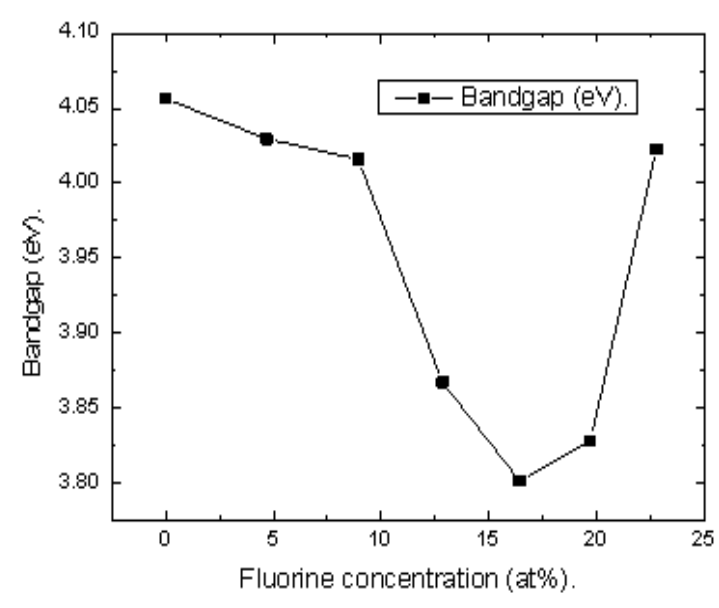

Figure 6. Optical Band gap for $\mathrm{F}: \mathrm{SnO}_{2}$ thin films

\subsection{Pd-F:SnO ${ }_{2}$ Films}

Different thin films for Pd-F: $\mathrm{SnO}_{2}$ were deposited. The film with the best optical transparency was the best choice for making a transparent thin film gas sensor. The optical band gap for $2.7 \mathrm{at} \% \mathrm{Pd}: \mathrm{SnO}_{2}$ thin films doped with fluorine, with the concentration of the dopant, ranging from $0 \mathrm{at} \% \mathrm{~F}$ to $19.28 \mathrm{at} \% \mathrm{~F}$ as shown in fig 7 . It can be seen that the initial band gap of $2.7 \mathrm{at} \% \mathrm{Pd}: \mathrm{SnO}_{2}$ thin films was $4.1135 \mathrm{eV}$. When fluorine is incorporated to have a co-doped $\mathrm{Pd}-\mathrm{F}: \mathrm{SnO}_{2}$ thin film, the band gap remains slightly above $4.05 \mathrm{eV}$. Increasing the fluorine dopant concentration from zero to the optimum level of about $16.04 \mathrm{at} \% \mathrm{~F}$ led to a narrowing effect on the band gap. The $\mathrm{E}_{\mathrm{g}}$ was found to increase sharply for higher levels of $\mathrm{F}$ doping beyond this level.

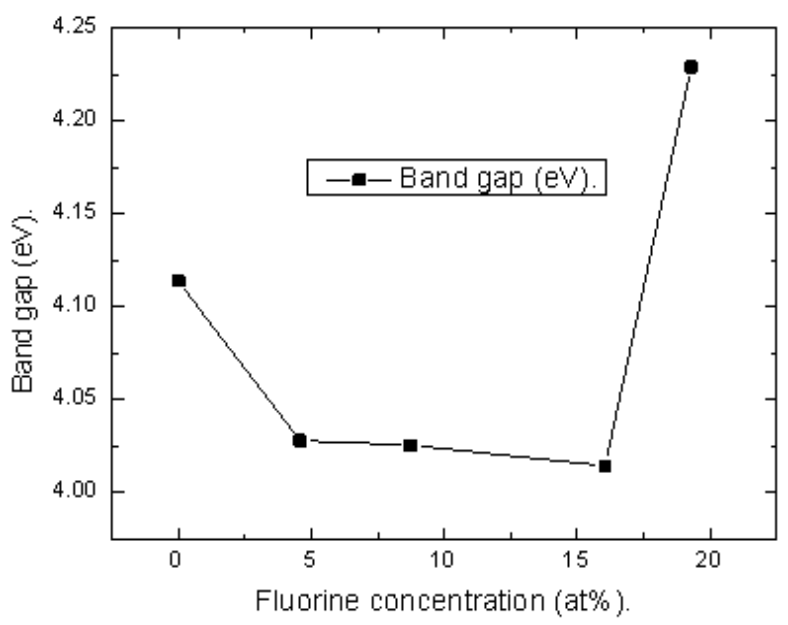

Figure 7. Optical Band gap for Pd-F: $\mathrm{SnO}_{2}$ thin films

Fig 8 below shows the effect of both annealing and passivation on the band gap of Pd-F: $\mathrm{SnO}_{2}$ thin films. On annealing the thin films, the band gap was found to decrease from $4.02 \mathrm{eV}$ to $3.91 \mathrm{eV}$. This is because apart from eliminating the oxygen vacancies, annealing process also localizes the oxygen atoms at interstitials positions. The induced oxygen interstitials form separate band defects in the band gap region, causing the reduction in $\mathrm{E}_{\mathrm{g}}$ value [28]. 


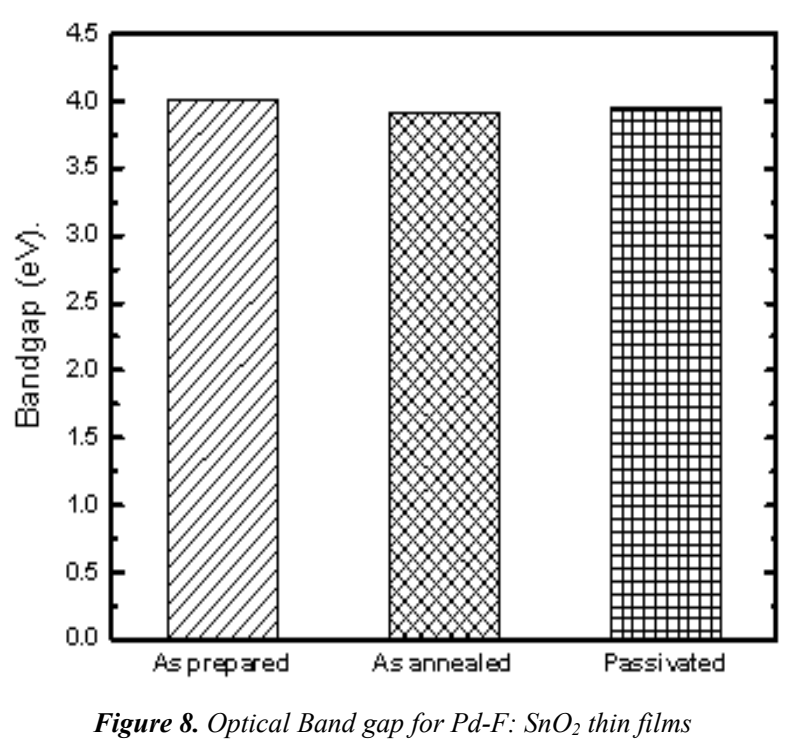

The optical band gap of Pd-F: $\mathrm{SnO}_{2}$ thin films was found to increase from $3.91 \mathrm{eV}$ to $3.94 \mathrm{eV}$ as a result of passivation on the thin films. The increase in the value of the optical band gap can be attributed to creation of oxygen vacancies as a result of annealing of the thin films in oxygen deficient atmosphere [18].

\section{Conclusion}

Pd-F: $\mathrm{SnO}_{2}$ thin films prepared by spray pyrolysis technique have good optical characteristics for gas sensing applications. The band gap has been found to narrow with increase in fluorine incorporation, this observation was ascribed to the incorporation of $\mathrm{F}^{-}$ions in the crystal lattice, which gives rise to donor levels in the $\mathrm{SnO}_{2}$ band gap which is an essential characteristics for the gas sensor application. Both annealing and passivation have been found to cause very insignificant change in Pd-F: $\mathrm{SnO}_{2}$ band gap, meaning that passivated gas sensor when exposed to elevated temperature will not be severely affected.

\section{Acknowledgements}

The authors would wish to acknowledge the financial support by NACOSTI and IPPS. Gratefully thanked are University of Nairobi and Kenyatta University for access of equipments and the technical staffs of both universities, in particular Miss Everyline Akinyi and Mr. Abraham, for their advices while carrying out the experiments in the laboratory.

\section{References}

[1] Calnan, S. "Applications of Oxide Coatings in Photovoltaic Devices", Coatings,vol 4(1), pp 162 - 202, 2014.

[2] Mishra, R. L., Mishra, S.K and Prakash, S.G. "Optical and Gas Sensing Characteristics of Tin-Dioxide Nano-Crystalline Thin Films." Journal of Ovonic Research, vol 5, pp77-85, 2009.
[3] Shamala, K.S., Murthy, L.C.S and Rao, K.N. "Studies on tin oxide films prepared by electron beam evaporation and spray pyrolysis methods" Bull. Mater. Sci. vol 27, pp295-301, 2004.

[4] Subramanian, N.S, Santhi, B, Sundareswaran, S, Venkatakrishnan, K.S. "Studies on Spray Deposited $\mathrm{SnO}_{2}$, $\mathrm{Pd}: \mathrm{SnO}_{2}$ and $\mathrm{F}: \mathrm{SnO}_{2}$ Thin Films for Gas Sensor Applications",Synthesis and Reactivity in Inorganic. Metal-Organic, and Nano-Metal Chemistry,vol 36,pp 131-135, 2006.

[5] Chowdhury, F.R., Chowdhury, S., Firozhasan and Begum, T. "Optical properties of Undoped and indium Doped Tin Oxide Thin Films". Journal of Bangladesh Academy of Sciences, vol 35, pp 99-111, 2011.

[6] Ikhmayies, S.J and Ahmad - Bitar, R.N. "Effect of Processing on the Electrical Properties of Spray-Deposited $\mathrm{SnO}_{2}: \mathrm{F}$ Thin Films". American Journal of Applied Sciences, vol 5, pp 672-677, 2008.

[7] Salehi, H., Aryadoust, M., and Farbod, M. "Electronic and Structural Properties of Tin Dioxide in Cubic Phase". Iranian Journal of Science \& Technology, Trans. A, vol 34, (A2), pp 131-138, 2010.

[8] Rakhshani, E.A., Makdisi, Y and Ramazaniyan, A.H. "Electronic and optical properties of fluorine-doped tin oxide films”. J. Applied Phys. vol 83, pp 1049-1057, 1998.

[9] Mohammad, T.M. "Performance and characteristics of Al-PbS/SnO 2 : F selective coating system for photothermal energy conversion”. Solar Energy Mater. Vol 20,pp 297-305, 1990.

[10] Yadav, A. A., Masumdar, E. U., Moholkar, A. V., Rajpure, K. Y and Bhosale, C. H. "Gas Sensing of Fluorine Doped Tin Oxide Thin Films Prepared by Spray Pyrolysis". Journal of Sensors \& Transducers, vol 92, pp55-60, 2008.

[11] Díaz, R (2002). Tin oxide thin films: electronic properties and growth mechanism under electrochemical control. University of Barcelona, Barcelona, Spain.

[12] Miller, T.A., Bakrania, S.D., Perez, C and Woondridge. Nanostructured Tin Dioxide Materials for Gas Sensor Applications. American Scientific Publishers, Michgan USA, , pp 1-24, 2006.

[13] Vaezi M.R. "Effects of surface modification on the recovery time and stability of nano structured tin oxide thick films gas sensors". International Journal of electronics Transactions B. Applications, vol 20, pp 1-8, 2007.

[14] Adamyan, A.Z., Adamyan, Z.N., Aroutiounian, V.M., Schietbaum, K.D and Han, S-D. "Improvement and Stabilization of Thin - Film Hydrogen Sensors Parameters". Armenian Journal of Physics, vol 2, pp 200-212, 2009.

[15] Moure- Flores, F., Guillen - Gervauntes, A., Nieto-Zapeda, K.E., Quinones- Galvan, JG., Hernandez- Hernandez. A., Olvera, M.G and Melendez- Lira, M. " $\mathrm{SnO}_{2}$ Thin Films Deposited by RF Magnetron Sputtering: Effect of the $\mathrm{SnF}_{2}$ Amount in the Target on the Physical Properties". Revista Mexicana de Fisica, vol 59,pp 335-338, 2013.

[16] Al-Delaimy, S.M and Basheer, R.J. "Annealing Effects on Structural and Optical Properties of $\mathrm{SnO}_{2}$ Thin Films". J.Edu. \& Sci.,vol 21, pp 99-109, 2008. 
[17] Senthilkumara, V., Vickramana*, P., Joseph Princeb, J., Jayachandranc, $M$ and C. Sanjeevirajad. "Effects of annealing temperature on structural, optical, and electrical properties of antimony-doped tin oxide thin films". Philosophical Magazine Letters, vol 90, pp 337-347, 2010.

[18] Jain, V.K., Kumar, P and Vijay, Y.K. "Preparation of Nanostructure $\mathrm{ZnO}-\mathrm{SnO}_{2}$ Thin Films For Optoelectronic Properties and Post Annealing Influence". World Academy of Sciences, Engineering and Technology, vol 72, pp 1575-1577, 2012.

[19] Jebbari, N., Kamoun, N and Bennaceur, R. "Effect of $\mathrm{SnCl}_{4}$ concentration on F: $\mathrm{SnO}_{2}$, deposited by chemical spray pyrolysis". In the proceedings of International Renewable Energy Congress, Souse, Tunisia,vol 2, pp 276-279, 2010.

[20] Bochenkov, V. E and Sergeev, G. B. "Sensitivity, Selectivity, and Stability of Gas-Sensitive Metal-Oxide Nanostructures and their Applications" American Scientific Publishers, Russia, vol 3, pp 31-52, 2010.

[21] Ozaki, Y., Suzuki, S., Morimitsu, M and Matsunaga, M. "Enhanced long-term stability of $\mathrm{SnO}_{2}$-based $\mathrm{CO}$ gas sensors modified by sulfuric acid treatment". Sensors and Actuators $B$, vol 62, pp $220-225,2000$

[22] Radecka, M., Zakrzewska, K. and Rekas, M. " $\mathrm{SnO}_{2}-\mathrm{TiO}_{2}$ solid solutions for gas sensors", Sensors and Actuators B, vol 47, pp194-204, 1998.

[23] Yousaf, S.A and Ali, S. "The Effect of Fluorine Doping on
Optoelectronic Properties of Tin-Dioxide (F:SnO $\left.{ }_{2}\right)$ Thin Films". Journal of Natural Sciences and Mathematics, vol 48, pp 43-50, 2008.

[24] Sandipan R, Gupta P.S. and Gurdeep S. "Electrical and Optical properties of sol-gel prepared Pd-doped $\mathrm{SnO}_{2}$ thin films: Effect of multiple layers and its use as room temperature methane gas sensor", Journal of Ovonic Research,vol 6(1), pp 63-74, 2010.

[25] Sa'nchez-Garcia, M., Maldonado. Castaneda, L., SilvaGonzalez, R and Olvera, M.L. "Characterization of $\mathrm{SnO}_{2}: \mathrm{F}$ Thin Films Deposited by Ultrasonic Spray Pyrolysis: Effect of Water Content in Solution and Substrate Temperature". Materials, Sciences and Applications, vol 3, pp 690-696, 2012.

[26] Odari, B.V., Mageto, M., Musembi, R., Othieno, H., Gaitho, F., and Muramba, V. "Optical and Electrical Properties of Pd Doped $\mathrm{SnO}_{2}$ Thin Films Deposited by Spray Pyrolysis". Australian Journal of Basic and applied Sciences, vol 7(2), pp 89-98, 2013.

[27] Fatema R.C, Shamima C, Firoz H and Tahmina B. "Optical properties of undoped and indium-doped tin oxide thin films", Journal of Bangladesh Academy of Sciences, vol 35(1): pp 99-111, 2011.

[28] Baco, S., Chik, A and Tassin , F.Md. "Study on Optical Properties of Tin Oxide Thin Films at Different Annealing Temperatures". Journal of Science and Technology, , vol 4, pp 61-72, 2012. 